\title{
Relationship of Deoxynivalenol Content in Grain, Chaff, and Straw with Fusarium Head Blight Severity in Wheat Varieties with Various Levels of Resistance
}

\author{
Fang Ji ${ }^{1,2,3,4}$, Jirong Wu ${ }^{1,2,3,4}$, Hongyan Zhao ${ }^{1,2,3,4}$, Jianhong Xu ${ }^{1,2,3,4}$ and Jianrong Shi ${ }^{1,2,3,4, *}$
}

1 State Key Laboratory Breeding Base of Food Quality and Safety in Jiangsu Province, Ministry of Agriculture, Nanjing 210014, China; E-Mails: jifang625@126.com (F.J.); yangzhouwjr@126.com (J.W.); hongyanz8910@126.com (H.Z.); xjh@jaas.ac.cn (J.X.)

2 Key Laboratory of Control Technology and Standardfor Agro-product Safety and Quality, Ministry of Agriculture, Nanjing 210014, China

3 Key Laboratory of Agro-product Safety Risk Evaluation (Nanjing), Ministry of Agriculture, Nanjing 210014, China

4 Institute of Food Quality and Safety, Jiangsu Academy of Agricultural Sciences, Nanjing 210014, China

* Author to whom correspondence should be addressed; E-Mail: jianrong63@126.com; Tel.: +86-25-8439-0603; Fax: +86-25-8439-2001.

Academic Editor: Richard A. Manderville

Received: 12 November 2014 / Accepted: 22 February 2015 / Published: 5 March 2015

\begin{abstract}
A total of 122 wheat varieties obtained from the Nordic Genetic Resource Center were infected artificially with an aggressive Fusariumasiaticum strain in a field experiment. We calculated the severity of Fusarium head blight (FHB) and determined the deoxynivalenol (DON) content of wheat grain, straw and glumes. We found DON contamination levels to be highest in the glumes, intermediate in the straw, and lowest in the grain in most samples. The DON contamination levels did not increase consistently with increased FHB incidence. The DON levels in the wheat varieties with high FHB resistance were not necessarily low, and those in the wheat varieties with high FHB sensitivity were not necessarily high. We selected 50 wheat genotypes with reduced DON content for future research. This study will be helpful in breeding new wheat varieties with low levels of DON accumulation.
\end{abstract}


Keywords: deoxynivalenol; FHB severity; wheat varieties

\section{Introduction}

Fusarium head blight (FHB) is a fungal disease that affects numerous small grain species [1-4]. This disease is caused by members of the Fusarium graminearum species complex, which consists of at least 16 phylogenetically distinct species [5]. FHB reduces kernel set and kernel weight, which contribute to significant grain yield losses. The disease also decreases the nutritive and baking quality of grain through degradation of proteins. Mycotoxins may accumulate to unacceptable levels, making harvested grain and their byproducts unsuitable for human and animal consumption.

Deoxynivalenol (DON) is one of the most economically important trichothecenes produced by F. graminearum. It is stable at high temperatures and is soluble in water and some polar solvents [6]. DON is also referred to as vomitoxin, due to its ability to induce vomiting, especially in pigs [7]. In plants, DON delays seed germination and subsequent plant growth and development [8]. At the cellular level, the main toxic effect of DON is inhibition of protein synthesis via binding to ribosomes [9]. Additionally, DON acts as a virulence factor and plays an essential role in the spread of $F$. graminearum after the initial injection of a wheat plant [10].

Since the 1990s, interest in the health benefits and safety of cereal products has increased. Alimentary mycotoxin accumulation is a risk associated with the consumption of infected grain [11], and this has resulted in the establishment of maximum permissible DON levels for grain destined for human consumption. In China, the maximum permissible level of DON in cereals and their byproducts is $1 \mathrm{mg} / \mathrm{kg}[12]$.

Wheat straw and chaff are often used for feedstuff, but may be unsuitable for animal consumption if contaminated by Fusarium toxins. Kang and Buchenauer (2000) and Matthäus et al. (2004) reported that natural contamination of feed by Fusarium toxins resulted in altered nutrient composition and marked modification of cell wall compounds in the infected grain due to higher activities of protease, amylase, and several NSP-degrading enzymes [13,14]. K. Seeling et al. demonstrated that feeding animals with wheat and wheat chaff contaminated with the Fusarium toxins DON and zearalenone (ZON) caused slight changes in ruminal nutrient degradability and in rumen physiological parameters, probably due to fungus-related modifications of the grain [15].

The development of FHB-resistant cultivars has been effective in reducing damage caused by the disease, However, resistance to FHB is affected by the relationship between symptom intensity and toxin production [16-18]. Understanding the relationship between FHB and DON accumulation could be important in predicting the risks of mycotoxins in food, and may aid in the development of a more reliable and rational strategy for managing the FHB disease complex and reducing DON production. Numerous attempts have been made to relate disease incidence or severity to mycotoxin concentrations and the results have varied [19]. Despite the fact that most studies reported positive correlations between disease incidence and mycotoxin accumulation, the quantity of mycotoxins per unit of disease index differed considerably and some studies failed to find a significant relationship [20]. The warm and humid climate in Jiangsu Province, China, during wheat flowering is favorable for the development of FHB epidemics. In this study, 250 winter wheat varieties obtained from the Nordic Genetic Resource Center 
in Alnarp, Sweden, for FHB resistance in China (data not shown), we selected 122 varieties that exhibited stable type II resistance to examine the relationship between DON content and FHB severity and to screen for wheat genotypes with reduced DON content. In addition, we measured the concentrations of DON in the grain, chaff and straw of these varieties. Our results mayfacilitate the selection of varieties used for animal feed.

\section{Results}

\subsection{FHB Severity in Wheat Cultivars}

During an FHB epidemic in Jiangsu Province, China, in 2012 [21], the rate of infected spikelets was as low as $24 \%$ in the Sumai-3 cultivar, which exhibited the highest resistance, but was as high as $89 \%$ in susceptible cultivars. In this study, we found a large range of genetic variation among the varieties in the severity of FHB infection. The occurrence of infected spikelets was less than $25 \%$ in eleven varieties and greater than $89 \%$ in 26 varieties, and the remaining varieties exhibited intermediate levels of resistance to FHB (Table 1).

Table 1. Fusarium head blight (FHB) severity for selected wheat varieties from Sweden based on field-grown plants in 2012.

\begin{tabular}{|c|c|c|c|}
\hline NO. & Accession name & Origin & PIS $^{1}$ \\
\hline 1 & Loyal & Sweden & $31.69 \pm 10.56$ \\
\hline 2 & Hereford & Sweden & $24.34 \pm 7.64$ \\
\hline 3 & Skagen & Sweden & $23.35 \pm 6.04$ \\
\hline 4 & PAJ706-575A & Sweden & $45.82 \pm 22.35$ \\
\hline 5 & Mariboss & Sweden & $29.96 \pm 22.27$ \\
\hline 6 & Harnesk-7 & Sweden & $65.15 \pm 11.67$ \\
\hline 7 & IDUNA & Sweden & $39.17 \pm 16.00$ \\
\hline 8 & ANKAR & Sweden & $38.53 \pm 20.22$ \\
\hline 9 & ÅRING III & Sweden & 100.00 \\
\hline 10 & EROICA & Sweden & $22.61 \pm 19.92$ \\
\hline 11 & AROS & Sweden & $33.08 \pm 22.40$ \\
\hline 12 & BANCO & Sweden & $16.86 \pm 8.73$ \\
\hline 13 & NORRE & Sweden & $12.19 \pm 8.80$ \\
\hline 14 & STURE & Sweden & $56.28 \pm 31.01$ \\
\hline 15 & HELGE & Sweden & $14.40 \pm 0.73$ \\
\hline 16 & LINNA & Sweden & $29.39 \pm 12.89$ \\
\hline 17 & JYVÄ & Sweden & $95.14 \pm 6.82$ \\
\hline 18 & SIGYN II & Sweden & $100 \pm 0.00$ \\
\hline 19 & FOLKE & Sweden & $32.61 \pm 13.48$ \\
\hline 20 & HOLGER & Sweden & $24.12 \pm 9.90$ \\
\hline 21 & ALEMAR UST. HV. SG. & Sweden & $61.48 \pm 13.55$ \\
\hline 22 & GUSALEK K.17 & Sweden & $96.07 \pm 6.79$ \\
\hline 23 & LANTVETE FRÅN UPPSALA & Sweden & $100 \pm 0.00$ \\
\hline 24 & KOTTE & Sweden & $53.70 \pm 11.88$ \\
\hline
\end{tabular}


Table 1. Cont.

\begin{tabular}{|c|c|c|c|}
\hline NO. & Accession name & Origin & PIS ${ }^{1}$ \\
\hline 25 & EXTRA SQUAREHEAD & Sweden & $47.02 \pm 11.75$ \\
\hline 26 & RENODLAT SAMMETSVETE & Sweden & $91.61 \pm 6.20$ \\
\hline 27 & THULE II & Sweden & $92.81 \pm 11.84$ \\
\hline 28 & PANSAR II & Sweden & $29.68 \pm 6.63$ \\
\hline 29 & SVEA I & Sweden & $97.27 \pm 6.10$ \\
\hline 30 & PANSAR III & Sweden & $79.84 \pm 10.06$ \\
\hline 31 & GYLLEN II & Sweden & $85.29 \pm 10.23$ \\
\hline 32 & GLUTEN & Sweden & $93.75 \pm 12.50$ \\
\hline 33 & BORG & Sweden & $89.91 \pm 14.39$ \\
\hline 34 & PÄRL II & Sweden & $37.50 \pm 17.68$ \\
\hline 35 & ROBUR & Sweden & $26.34 \pm 10.49$ \\
\hline 36 & SEBA & Sweden & $68.30 \pm 11.44$ \\
\hline 37 & VIRGO & Sweden & $88.38 \pm 18.02$ \\
\hline 38 & SOLID & Sweden & $40.82 \pm 15.72$ \\
\hline 39 & HILDUR & Sweden & $17.09 \pm 6.66$ \\
\hline 40 & HANKKIJAN ILVES & Sweden & $39.52 \pm 10.72$ \\
\hline 41 & Harnesk-5 & Sweden & $24.68 \pm 9.89$ \\
\hline 42 & GUSALEK K.10 A & Sweden & $38.41 \pm 23.08$ \\
\hline 43 & KOSACK & Sweden & $46.04 \pm 11.00$ \\
\hline 44 & MK 2-114 & Sweden & $74.57 \pm 11.86$ \\
\hline 45 & MK 2-302 & Sweden & $32.31 \pm 6.84$ \\
\hline 46 & MK 2-304 & Sweden & $85.23 \pm 17.94$ \\
\hline 47 & MK 2-306 & Sweden & $95.56 \pm 9.94$ \\
\hline 48 & MK 2-313 & Sweden & $27.27 \pm 6.43$ \\
\hline 49 & MK 2-502 & Sweden & $41.36 \pm 10.15$ \\
\hline 50 & MK 2-503 & Sweden & $100.00 \pm 0.00$ \\
\hline 51 & MK 2-506 & Sweden & $46.11 \pm 16.35$ \\
\hline 52 & MK 2-508 & Sweden & $31.11 \pm 12.57$ \\
\hline 53 & MK 2-542 & Sweden & $59.82 \pm 15.41$ \\
\hline 54 & MK 2-543 & Sweden & $83.43 \pm 9.19$ \\
\hline 55 & MK 2-547 & Sweden & $97.37 \pm 5.26$ \\
\hline 56 & MK 2-548 & Sweden & $21.67 \pm 21.62$ \\
\hline 57 & MK 2-556 & Sweden & $90.73 \pm 11.73$ \\
\hline 58 & MK 2-557 & Sweden & $77.06 \pm 11.22$ \\
\hline 59 & MK 2-558 & Sweden & $84.31 \pm 13.25$ \\
\hline 60 & MK 2-564 & Sweden & $63.92 \pm 25.45$ \\
\hline 61 & SALUT & Sweden & $53.91 \pm 12.70$ \\
\hline 62 & ØSTBY & Sweden & $30.81 \pm 9.26$ \\
\hline 63 & MK 2-501 & Sweden & $59.04 \pm 11.22$ \\
\hline 64 & MK 2-510 & Sweden & $94.18 \pm 8.85$ \\
\hline 65 & PORTAL & Sweden & $30.01 \pm 10.00$ \\
\hline 66 & TJELVAR & Sweden & $45.51 \pm 9.95$ \\
\hline 67 & TRYGGVE & Sweden & $88.81 \pm 10.62$ \\
\hline 68 & MK 2-549 & Sweden & $79.50 \pm 11.95$ \\
\hline 69 & MK 2-566 & Sweden & $91.67 \pm 14.43$ \\
\hline
\end{tabular}


Table 1. Cont.

\begin{tabular}{|c|c|c|c|}
\hline NO. & Accession name & Origin & PIS $^{1}$ \\
\hline 70 & MK 2-651 & Sweden & $42.84 \pm 11.66$ \\
\hline 71 & MK 2-656 & Sweden & $66.51 \pm 28.36$ \\
\hline 72 & MK 2-659 & Sweden & $39.18 \pm 13.15$ \\
\hline 73 & MK 2-660 & Sweden & $61.33 \pm 21.33$ \\
\hline 74 & MK 2-775 & Sweden & $44.96 \pm 7.58$ \\
\hline 75 & MK 2-780 & Sweden & $88.18 \pm 21.70$ \\
\hline 76 & MK 2-786 & Sweden & $86.93 \pm 15.12$ \\
\hline 77 & MK 2-787 & Sweden & $44.74 \pm 12.32$ \\
\hline 78 & PANU & Sweden & $65.90 \pm 34.88$ \\
\hline 79 & KONGE III & Sweden & $37.50 \pm 15.52$ \\
\hline 80 & TYSTOFTE SMAAHVEDE & Sweden & $34.03 \pm 10.88$ \\
\hline 81 & RENTAL & Sweden & $57.33 \pm 13.20$ \\
\hline 82 & STAVA & Sweden & $53.88 \pm 15.44$ \\
\hline 83 & RUDOLF RUBIN & Sweden & $90.58 \pm 13.79$ \\
\hline 84 & KIRSTEN & Sweden & $42.80 \pm 11.91$ \\
\hline 85 & LONE & Sweden & $43.68 \pm 8.71$ \\
\hline 86 & BRANDT & Sweden & $40.56 \pm 11.73$ \\
\hline 87 & KARAT & Sweden & $39.61 \pm 17.13$ \\
\hline 88 & MK 2-101 & Sweden & $41.43 \pm 17.05$ \\
\hline 89 & MK 2-113 & Sweden & $49.57 \pm 24.98$ \\
\hline 90 & MK 2-116 & Sweden & $71.81 \pm 24.64$ \\
\hline 91 & MK 2-122 & Sweden & $94.44 \pm 13.61$ \\
\hline 92 & MK 2-130 & Sweden & $29.91 \pm 10.39$ \\
\hline 93 & MK 2-316 & Sweden & $47.09 \pm 15.38$ \\
\hline 94 & MK 2-317 & Sweden & $69.01 \pm 13.76$ \\
\hline 95 & MK 2-337 & Sweden & $64.83 \pm 15.38$ \\
\hline 96 & MK 2-567 & Sweden & $57.99 \pm 39.13$ \\
\hline 97 & MK 2-655 & Sweden & $68.97 \pm 26.56$ \\
\hline 98 & MK 2-138 & Sweden & $32.40 \pm 16.47$ \\
\hline 99 & MK 2-679 & Sweden & $81.00 \pm 7.12$ \\
\hline 100 & MK 2-788 & Sweden & $70.70 \pm 10.31$ \\
\hline 101 & MK 2-847 & Sweden & $25.99 \pm 13.17$ \\
\hline 102 & Saxild & Sweden & $37.17 \pm 18.92$ \\
\hline 103 & Abba & Sweden & $33.86 \pm 4.74$ \\
\hline 104 & Konsul & Sweden & $100.00 \pm 0.00$ \\
\hline 105 & Rektor & Sweden & $35.89 \pm 8.00$ \\
\hline 106 & Stakado & Sweden & $100.00 \pm 0.00$ \\
\hline 107 & Kerimäkeläinen & Sweden & $95.45 \pm 9.09$ \\
\hline 108 & Sampo & Sweden & $95.83 \pm 9.32$ \\
\hline 109 & Väinö & Sweden & $87.20 \pm 11.37$ \\
\hline 110 & Speltti Vaalea & Sweden & $67.79 \pm 19.61$ \\
\hline 111 & Speltti Ruskea Baulander & Sweden & $56.30 \pm 18.53$ \\
\hline 112 & Kökar & Sweden & $31.96 \pm 8.09$ \\
\hline 113 & Olympia & Sweden & $77.45 \pm 13.20$ \\
\hline
\end{tabular}


Table 1. Cont.

\begin{tabular}{cccc}
\hline NO. & Accession name & Origin & PIS $^{\mathbf{1}}$ \\
\hline 114 & H 8703 & Sweden & $100.00 \pm 0.00$ \\
115 & H 8196 & Sweden & $100.00 \pm 0.00$ \\
116 & H 8202 & Sweden & $100.00 \pm 0.00$ \\
117 & H 8222 & Sweden & $76.78 \pm 35.98$ \\
118 & H 8296 & Sweden & $34.72 \pm 28.69$ \\
119 & H 8300 & Sweden & $88.75 \pm 15.56$ \\
120 & H 8305 & Sweden & $19.57 \pm 7.03$ \\
121 & H 8310 & Sweden & $94.44 \pm 9.62$ \\
122 & H 8311 & Sweden & $33.55 \pm 7.08$ \\
- & Control cultivar & - & - \\
- & Annong 8455 & China & $89.65 \pm 2.33$ \\
- & Sumai 3 & China & $24.21 \pm 9.04$ \\
\hline \multicolumn{4}{c}{ PIS is the percentage of infected spikelets. }
\end{tabular}

\subsection{Deoxynivalenol (DON) Levels in Wheat Grain, Straw, and Glume Tissues after Artificial} Inoculation of Wheat Ears

A total of 122 wheat varieties were inoculated, and DON levels were determined in a total of 366 grain, straw, and glume samples. DON content was higher in glumes than in straw in $90.16 \%$ of the samples, and higher in straw than in grain samples in $73.77 \%$. The DON content was higher in glumes than in grain in $95.90 \%$ of the samples (Figure 1). One-way analysis of variance (ANOVA) showed significant differences in DON content among grain, straw, and glumes $(F=42.20$, $p<0.0001)$. The different plant sample types showed positive correlations $\left(r_{\text {grain }} v\right.$ s. straw $=0.261 * *$, $r_{\text {grain } v \text { s. glume }}=0.251 * *$, and $r_{\text {straw } v \text { s. glume }}=0.879 * *$ ). Although differences in mycotoxin content were large, the distribution of DON in plant tissues exhibited a distinct pattern (Table 2).

Table 2. Deoxynivalenol (DON) levels in samples of various wheat tissues determined using High Performance Liquid Chromatography-tandem Mass Spectrometry.

\begin{tabular}{cccccc}
\hline \multicolumn{6}{c}{ DON (mg/kg) } \\
\hline Tissue & $\boldsymbol{n}$ & Mean $^{*}$ & Median & Max & Min \\
\hline grain & 122 & $3.88^{\mathrm{A}}$ & 2.38 & 23.46 & 0.16 \\
straw & 122 & $15.30^{\mathrm{B}}$ & 7.85 & 123.74 & 0.04 \\
glume & 122 & $20.95^{\mathrm{C}}$ & 19.13 & 55.42 & 1.15 \\
\hline
\end{tabular}

*: Values in the same column with different capital letters were significantly different $(\alpha=0.01)$; Different letters within a column represent significant difference at $p=0.01$. 


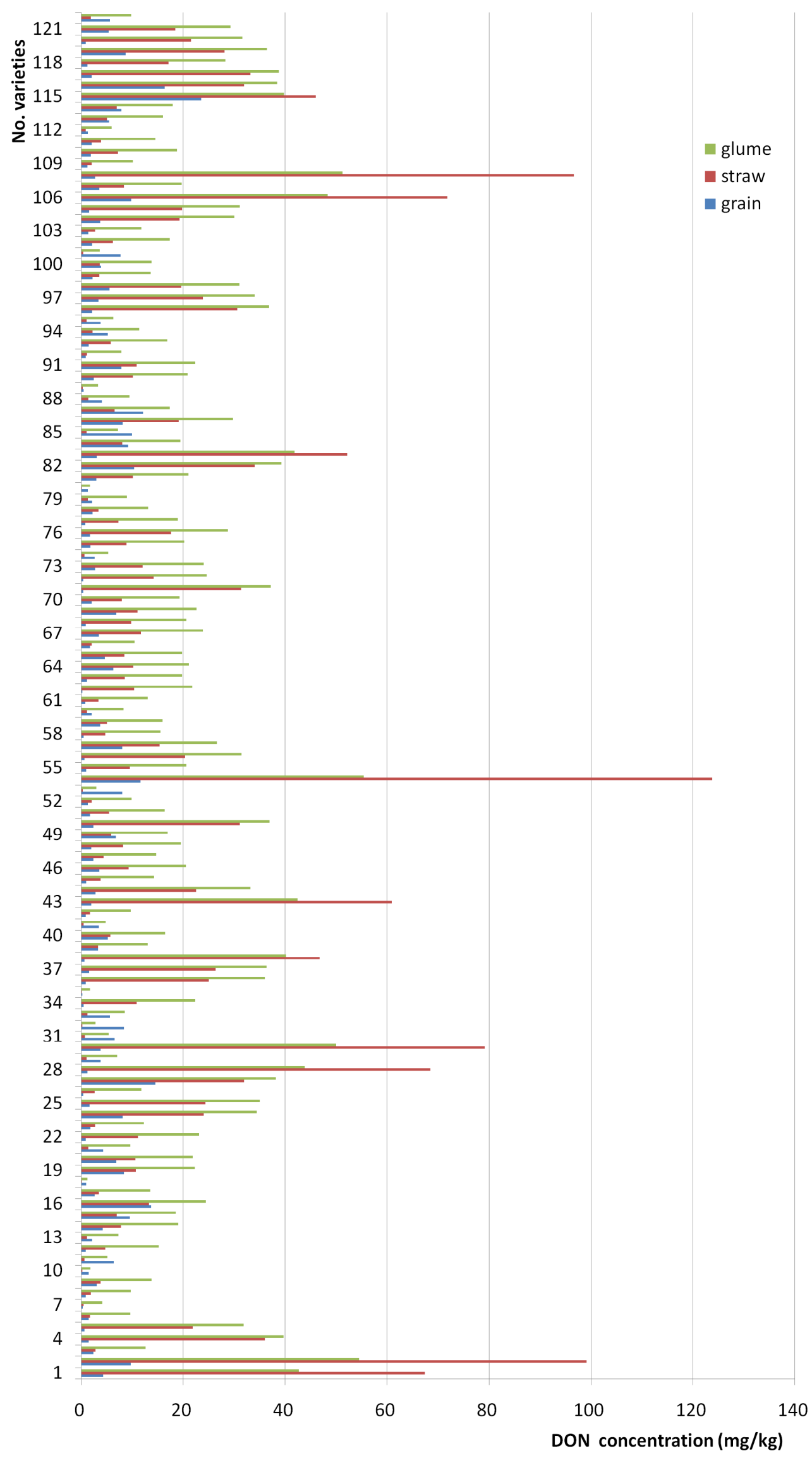

Figure 1. Distribution of deoxynivalenol in grain, glume and straw of wheat with different varieties. 


\subsection{DON Levels in Tissues from Wheat Varieties Exhibiting Differing FHB Disease Severity}

To better understand how the level of DON contamination varied with FHB severity, we divided the entire dataset into three levels of FHB severity relative to the severity of FHB according to the control cultivars (Figure 2$):<25 \%(n=11$, mean $=20.08 \%), 25 \%-89 \%(n=85$, mean $=52.94 \%)$, and $>89 \%$ $(n=26$, mean $=96.30 \%)$.

The DON contamination levels did not increase consistently with increasing FHB severity (Figure 2). The average and median DON levels were the highest in all three wheat tissues when the FHB severity was greater than $89 \%$. In the grain and the straw, the average and median DON levels were lowest when the FHB severity was between $25 \%$ and $89 \%$, whereas the lowest average and median levels in the glume occurred when the FHB severity was below $25 \%$. In general, the DON levels in the wheat varieties that were highly resistant to FHB were not necessarily low, and the DON levels in the varieties that were highly sensitive to FHB were not necessarily high.
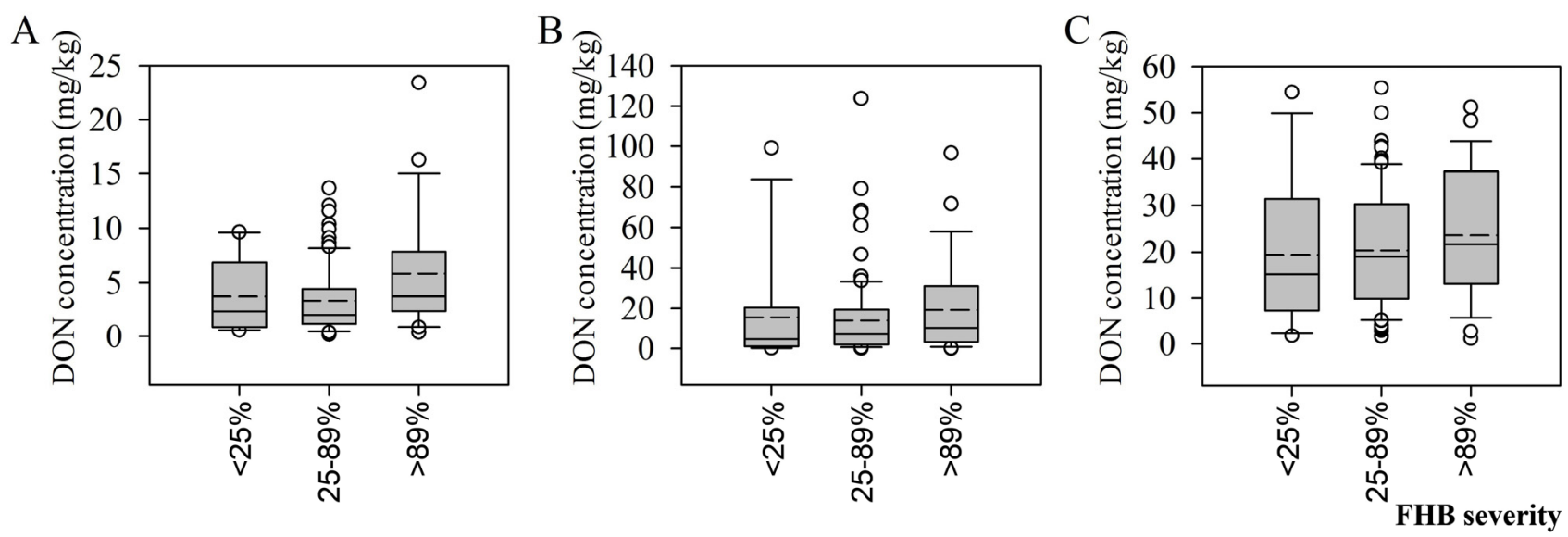

Figure 2. Box plots of the distribution of deoxynivalenol (DON) levels in wheat tissues ((A): grain; (B): straw; (C): glumes) inoculated with Fusarium graminearum at various levels of Fusarium head blight disease severity. Solid and dashed lines indicate medians and means, respectively. The box boundaries indicate the $75 \%$ and $25 \%$ quartiles. The whisker caps indicate 90 th and 10th percentiles and the circles indicate the 95th and 5th percentiles.

\subsection{Relationship between FHB Severity and DON Levels among Wheat Varieties and Selection of Wheat Genotypes with Reduced DON Content}

To further compare the variation of DON contamination levels with FHB severity among wheat varieties, the data were allocated into four groups according to average FHB severity and DON contamination level: (1) varieties with low FHB severity and low DON contamination; (2) varieties with low FHB severity and high DON contamination; (3) varieties with high FHB severity and low DON contamination; and (4) varieties with high FHB severity and high DON contamination (Figure 2). The horizontal and vertical lines represent the $y$ - and $x$-axis average values, respectively.

The relationship between DON content in grain and FHB severity is shown in Figure 3A. Groups 1, 2, 3, and 4 included 45, 25, 36, and 16 varieties, respectively. For the straw samples of the 122 wheat varieties, $41 \%$ were in group $1,16 \%$ in group $2,30 \%$ in group 3, and $13 \%$ in group 4 (Figure 3B). 
For the glume samples, 33\% were in group 1, 25\% in group 2, 26\% in group 3, and 16\% in group 4 (Figure 3C). Many of the samples exhibited low DON contamination levels (groups 1 and 3) and may correspond to varieties that would be useful for breeding new wheat varieties with low levels of DON accumulation.

Among the 122 varieties, 27 were consistently in group 1, six were consistently in group 2, 23 were consistently in group 3, and seven were consistently in group 4 . For both straw and glumes, 13 varieties were consistently in group 1, 14 were consistently in group 2, nine were consistently in group 3, and nine were consistently in group 4 . For both straw and grain, four varieties were consistently in group 1 and four varieties were consistently in group 3. For both grain and glumes, only six varieties were consistently in group 2 . The varieties in group 1 had low DON contamination levels not only in the grain but also in the straw and glume. These varieties were Skagen, IDUNA, ANKA, EROICA, BANCO, NORRE, ROBUR, HILDUR, Harnesk-5, MK 2-302, MK2-313, MK 2-506, MK 2-508, MK 2-547, SALUT, MK 2-549, MK 2-775, MK 2-787, KONGE III, TYSTOFTE SMAAHVEDE, MK 2-316, MK 2-317, MK 2-567, Abba, Speltti Vaalea, Kökar, and Olympia.
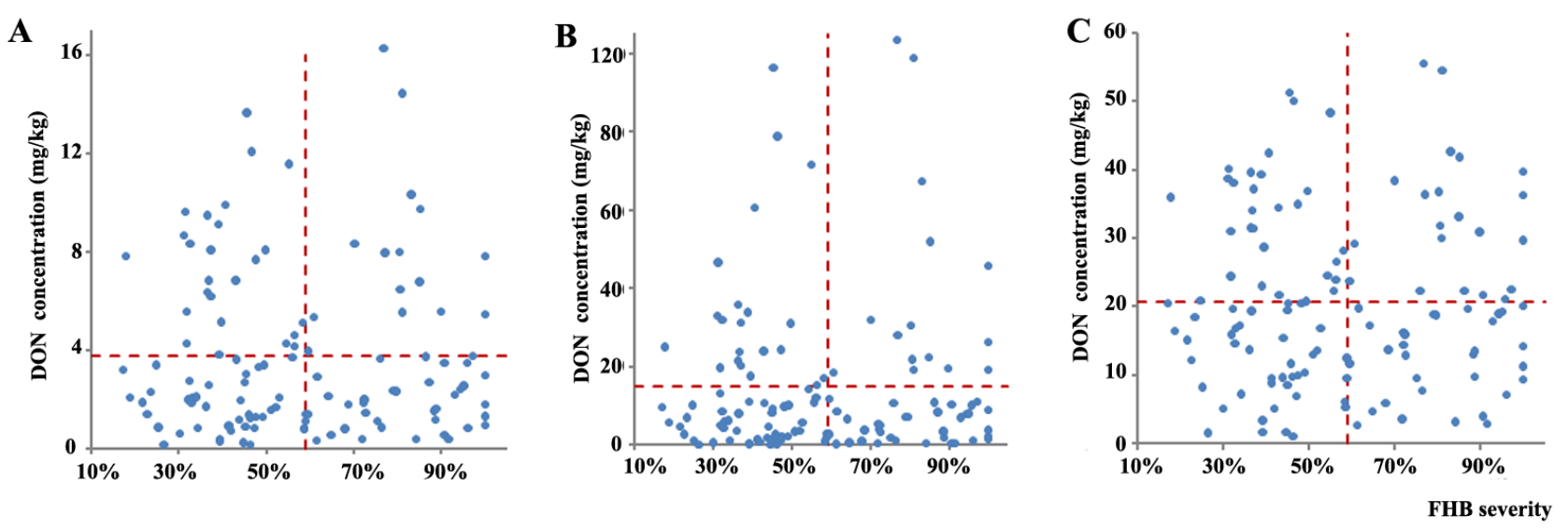

Figure 3. Relationship between Fusarium head blight (FHB) severity and deoxynivalenol levels in wheat tissues ((A): grain; (B): straw; $(\mathbf{C})$ : glumes). Dashed lines indicate the average FHB severity (59\%) and average concentration of DON ((A): $3.78 \mathrm{mg} / \mathrm{kg}$, (B): $14.77 \mathrm{mg} / \mathrm{kg},(\mathbf{C}): 20.65 \mathrm{mg} / \mathrm{kg}$ ) in 366 samples (grain samples = 122, straw samples = 122, glume samples $=122$ ).

The varieties in group 3 had low DON contamination levels in all three wheat tissues while exhibiting high FHB severity. These varieties were Harnesk-7, ÅRING III, JYVÄ, SIGYN II, LANTVETE FRÅN UPPSALA, RENODLAT SAMMETSVETE, SVEA I, GUSALEK K.10 A, MK 2-304, MK 2-306, MK 2-557, MK 2-558, MK 2-564, MK 2-501, TJELVAR, MK 2-651, MK 2-780, PANU, MK 2-113, MK 2-788, Konsul, Sampo and Speltti Ruskea Baulander. We selected these 50 varieties as wheat genotypes with reduced DON content for future studies.

\section{Discussion}

Resistance to FHB can be characterized as consisting of two components: resistance to initial penetration and resistance to pathogen spread in the host tissue [22]. In addition to the resistance mechanisms that determine the severity of FHB, other mechanisms may influence DON content in 
kernels, including degradation or conjugation of DON and tolerance to DON $[8,23,24]$. DON tolerance results in an increased level of resistance and inherent prevention of trichothecene accumulation [25]. DON production is an important factor in the overall pathogenesis of FHB. Several studies have reported a significant positive correlation between the incidence of FHB and DON concentration [20,26]. Snijders and Perkowski reported that reduced disease incidence in the field ensured reduced mycotoxin content of the grain [8]. Correlations between FHB ratings and DON content were high in segregating material and in a collection of varieties with different levels of FHB resistance [27,28]. Others have demonstrated a significant correlation between DON and the fungal biomass of the grain [18,20,29]. These results suggest that new cultivars could be selected based on disease symptoms to ensure low levels of DON.

Bai et al. identified some wheat cultivars with severe FHB symptoms and low DON levels, particularly in cultivars with moderate resistance to $F$. graminearum [20]. Chen et al. inoculated five wheat varieties with a strain of $F$. graminearum and found no correlation between DON concentration and FHB severity [30]. Liu also found no correlation between DON concentration and FHB severity in wheat, barley (Hordeum vulgare L.) and oats (Avena sativa L.) after inoculation with a complex of Fusarium species [23]. In natural contamination, there was also no correlation between FHB severity in wheat and DON concentration or between the presence of Fusarium and DON concentration [31-33]. These differences in results may be due to the differences in the genotypes planted, pathogen populations, weather conditions, or management practices among the various studies.

Certain genotypes can limit the development of mycelium in the grain, thereby protecting it from degradation and limiting the visual signs of attack, but those genotypes often have low tolerance to mycotoxins [20]. Conversely, other cultivars may exhibit severe FHB symptoms and low mycotoxin levels. Beyer et al. studied the moderately susceptible wheat cultivar Dekan, which can partially avoid infection and then limit DON accumulation in the kernels when infections cannot be avoided [34].

We found DON contamination to be highest in glumes, intermediate in the straw, and lowest in the grain. DON produced by FHB in wheat can also have physiological effects in other parts of the plant [25]. Between the chaff and the kernel, several physical barriers could potentially limit the movement of the fungus and therefore prevent DON to move from the point of initial infection on the glumes or chaff to the kernel [35]. Snijiders et al. and Doohan et al. reported the ability of the toxin to translocate from chaff to the grain [36,37]. Data from previous studies suggest that the highest accumulation of mycotoxins in the barley hull [38]. Legzdina et al. reported that hulless barley tends to be less prone to mycotoxin contamination than covered barley, assuming a similar level of field FHB severity [39]. Wang and Miller reported higher levels of DON in the chaff than in the kernel of wheat [40].

In mature plants, DON appears to circulate in the phloem, with concentration following a descending gradient from the rachis, through the lemmas and grain, to the peduncle [41]. In our results, we found that the DON content was lowest in grain, then in straw and highest in glume. Schroeder and Christensen injected spores into the rachis and showed that the pathogen was able to migrate within the plant and propagate more rapidly longitudinally than transversely. Contaminated straw and glume residues remaining on the soil surface can infect seedlings of the following crop during the vegetative growth stage [42].

In conclusion, understanding the relationship between FHB severity and mycotoxin contamination is important. The conditions under which this relationship is purely qualitative rather than quantitative are 
unclear. In China, the increased use of high-yielding wheat varieties with greater susceptibility to FHB has increased the incidence of mycotoxins, indicating that the goal of a breeding program should be to select for both mycotoxin resistance and grain yield.

\section{Materials and Methods}

\subsection{Reagents and Chemicals}

DON was obtained from Sigma-Aldrich (Shanghai, China) at a concentration of $100 \mu \mathrm{g} / \mathrm{mL}$ in acetonitrile. HPLC-grade acetonitrile and methanol were obtained from Merck (Darmstadt, Germany). Deionized water $\left(<8 \mathrm{M} \Omega \mathrm{cm}^{-1}\right.$ resistivity) was produced using a Milli-Q water purification system (Millipore, Bedford, MA, USA). All solvents were passed through $0.22-\mu \mathrm{m}$ cellulose filters (Jinteng, Tianjin, China) before use.

\subsection{Plant Material}

Winter wheat seeds were obtained from the Nordic Genetic Resource Center in Alnarp, Sweden. Sumai-3 (high resistance) and Annong-8455 (high susceptibility) cultivars were used as control varieties to define levels of FHB resistance $[43,44]$.

Winter wheat was grown according to current recommendations of integrated pest management, although applications of fungicide against Fusarium species were omitted. The field experiment was conducted at the Luhe experimental station, Jiangsu Academy of Agricultural Science (Luhe), Nanjing, China $\left(32^{\circ} 28.583^{\prime} \mathrm{N}, 118^{\circ} 38^{\prime} \mathrm{E}\right)$ in 2011 . Wheat was sown in late October in rows $150 \mathrm{~cm}$ in length and $33 \mathrm{~cm}$ apart with three replicates using a randomized block design.

An aggressive strain, F0613, was used to produce macroconidia in mung bean extraction liquid medium, as previously described [45]. The F0613 strain was isolated originally from diseased wheat grain in 2006 in Jiangsu Province. It belongs to Fusarium asiaticum, a member of the Fusarium graminearum species complex. At the heading stage, the middle spikelets of wheat flowers were inoculated with $10 \mu \mathrm{L}$ of the conidial suspension containing $1 \times 10^{5}$ spores $\mathrm{mL}^{-1}$. Twenty days after inoculation, the numbers of infected spikelets and spikelets per head were recorded. The percentage of infected spikelets was calculated for each head. The mean FHB severity of 50 heads was calculated and all the 50 heads were pool into one sample for further analysis [46].

\subsection{Mycotoxin Analysis}

\subsubsection{Preparation of Analytical Standard Solutions}

Individual stock standard solutions were prepared as prescribed by the manufacturer. The working dilution for the calibration curve was prepared using a sample extract from a blank wheat sample (matrix-matched standard curve).

\subsubsection{Sample Preparation}

Harvested grain samples were cleaned manually. The glume was separated from the kernel. Straw was chopped into $3.0-\mathrm{cm}$ segments that were subsequently pulverized. The grain was ground to a 
powder of 20-meshe fineness in a laboratory mill (Ika Werke, Staufen, Germany), and the chaff and straw were treated with liquid nitrogen and pulverized using a Moulinette 320-grinder (Moulinex, Barcelona, Spain). All samples were stored at $4{ }^{\circ} \mathrm{C}$ for a maximum of 7 day.

The finely ground samples $(10 \mathrm{~g})$ were weighed and extracted with $40 \mathrm{~mL}$ of acetonitrile:water:acetic acid (79:20:1 v/v/v) at $180 \mathrm{rpm}$ for $30 \mathrm{~min}$ [47].

After centrifugation at $3000 \mathrm{rpm}$ for $10 \mathrm{~min}, 0.5 \mathrm{~mL}$ of each final extract was diluted with acetonitrile:water:acetic acid (20:79:1, v/v/v) and filtered through a nylon filter $(13 \mathrm{~mm}$ in diameter, $0.22-\mu \mathrm{m}$ pore size) into an autosampler vial, capped and analyzed by LC-MS/MS [48].

\subsubsection{LC-MS/MS Analysis}

The LC-MS/MS system consisted of an Agilent 1200 HPLC, an Agilent 6410B triple-quadrupole mass spectrometer, and an Agilent MassHunter Workstation running Qualitative Analysis Version B.01.03 software (Agilent, Shanghai, China, 2001) for data acquisition and analysis. The analytical column was an XDB-C18 $(2.1 \times 150 \mathrm{~mm}, 3.5-\mu \mathrm{m}$ bead diameter; Agilent, Shanghai, China) column and the column temperature was held constant at $30{ }^{\circ} \mathrm{C}$. Nitrogen was used as a drying gas at $10 \mathrm{~L} / \mathrm{min}$. The capillary voltage was $4 \mathrm{kV}$, the nebulizer pressure was $25 \mathrm{psi}$, and the drying gas temperature was $350{ }^{\circ} \mathrm{C}$. Mycotoxins were analyzed via multiple reaction monitoring (MRM). Mass spectrometric parameters of the mycotoxins and the composition of the mobile phase have been described by Soleimany et al. [49].

Quantification was performed against a matrix-matched calibration curve. During method development, limits of detection (LOD) and quantification (LOQ) scores for each analyte were determined on the basis of the signal-to-noise rations of 3:1 and 10:1. The LOD and LOQ scores were 10 and $20 \mu \mathrm{g} / \mathrm{kg}$, respectively.

\subsection{Statistical Analysis}

All data are expressed as percentages or means \pm relative standard deviation (RSD) using MS Excel.

\section{Acknowledgments}

The authors wish to acknowledge the Nordic Genetic Resource Center in Alnarp, Sweden, for providing winter wheat seeds. The work was supported financially by the National Institute of Food and Agriculture, Special Fund for Agro-scientific Research in the Public Interest (201303088), the National Natural Science Foundation of China (31271988), the Jiangsu Agriculture Science and Technology Innovation Fund of China (CX(13)3092), the Science and Technology Planning Project of Jiangsu Province, China (BE2014738), and the National Agricultural Products Quality Safety Risk Assessment Program of China (GJFP2014006).

\section{Author Contributions}

Jianrong Shi and Fang Ji conceived and designed the experiments; Fang Ji performed the experiments, analyzed the data and wrote the paper; Jirong Wu conducted the field experiment and calculated the Fusarium head blight severity; Hongyan Zhao and Jianhong Xu contributed reagents/materials/analysis tools. 


\section{Conflicts of Interest}

The authors declare no conflict of interest.

\section{References}

1. Bai, G.; Shaner, G. Scab of wheat: Prospects for control. Plant Dis. 1994, 78, 760-766.

2. McMullen, M.; Jones, R.; Gallenberg, D. Scab of wheat and barley: A re-emerging disease of devastating impact. Plant Dis. 1997, 81, 1340-1348.

3. Parry, D.; Jenkinson, P.; McLeod, L. Fusarium ear blight (scab) in small grain cereals - A review. Plant Pathol. 1995, 44, 207-238.

4. Xu, X.-M.; Berrie, A. Epidemiology of mycotoxigenic fungi associated with fusarium ear blight and apple blue mould: A review. Food Addit. Contam. 2005, 22, 290-301.

5. Goswami, R.S.; Kistler, H.C. Heading for disaster: Fusarium graminearum on cereal crops. Mol. Plant Pathol. 2004, 5, 515-525.

6. EFSA. Opinion of the scientific panel on contaminants in the food chain on a request from the commission related to deoxynivalenol(don) as undesirable substance in animal feed. EFSA 2004, 73, 1-41.

7. Rotter, B.A.; Prelusky, D.B.; Pestka, J.L. Toxicology of deoxynivalenol (vomitoxin). J. Toxicol. Environ. Health 1996, 48, 1-34.

8. Snijders, C.; Perkowski, J. Effects of head blight caused by fusarium culmorum on toxin content and weight of wheat kernels. Phytopathology 1990, 80, 566-570.

9. Hussein, H.S.; Brasel, J.M. Toxicity, metabolism, and impact of mycotoxins on humans and animals. Toxicology 2001, 167, 101-134.

10. Maier, F.J.; Miedaner, T.; Hadeler, B.; Felk, A.; Salomon, S.; Lemmens, M.; Kassner, H.; Schäfer, W. Involvement of trichothecenes in fusarioses of wheat, barley and maize evaluated by gene disruption of the trichodiene synthase (Tri5) gene in three field isolates of different chemotype and virulence. Mol. Plant Pathol. 2006, 7, 449-461.

11. Gilbert, J.; Tekauz, A. Review: Recent developments in research on fusarium head blight of wheat in Canada. Can. J. Plant Pathol. 2000, 22, 1-8.

12. National Criterion of China. Maximum levels of mycotoxins in foods 2001. GB/T 2761-2011. Available online: http://down.foodmate.net/standard/sort/3/28221.html (accessed on 20 April 2011).

13. Kang, Z.; Buchenauer, H. Ultrastructural and cytochemical studies on cellulose, xylan and pectin degradation in wheat spikes infected by Fusarium culmorum. J. Phytopathol. 2000, 148, 263-275.

14. Matthäus, K.; Dänicke, S.; Vahjen, W.; Simon, O.; Wang, J.; Valenta, H.; Meyer, K.; Strumpf, A.; Zieseni, H.; Flachowsky, G. Progression of mycotoxin and nutrient concentrations in wheat after inoculation with Fusarium culmorum. Arch. Anim. Nutr. 2004, 58, 19-35.

15. Seeling, K.; Boguhn, J.; Strobel, E.; Danicke, S.; Valenta, H.; Ueberschar, K.H.; Rodehutscord, M. On the effects of Fusarium toxin contaminated wheat and wheat chaff on nutrient utilisation and turnover of deoxynivalenol and zearalenone in vitro (Rusitec). Toxicol. In Vitro 2006, 20, 703-711.

16. Miller, J.D.; Young, J.C.; Sampson, D.R. Deoxynivalenol and Fusarium head blight resistance in spring cereals. Phytopath. Z. 1985, 113, 359-367. 
17. Mirocha, C.J.; Xie, W.; Xu, Y.; Wilcoxson, R.D.; Woodward, R.P.; Etebarian, R.H.; Behele, G. Production of trichothecene mycotoxins by Fusarium graminearum and Fusarium culmorum on barley and wheat. Mycopathologia 1994, 128, 19-23.

18. Liu, W.-Z.; Langseth, W.; Skinnes, H.; Elen, O.N.; Sundheim, L. Comparison of visual head blight ratings-seed infection levels and deoxynivalenol production for assessment of resistance in cereals inoculated with Fusarium culmorum. Eur. J. Plant Pathol. 1997, 103, 589-595.

19. Hestbjerg, H.; Felding, G.; Elmholt, S. Fusarium culmorum infection of barley seedlings: Correlation between aggressiveness and deoxynivalenol content. J. Phytopathol. 2002, 150, 308-312.

20. Bai, G.H.; Plattner, R.; Desjardins, A.; Kolb, F.; McIntosh, R. Resistance to fusarium head blight and deoxynivalenol accumulation in wheat. Plant Breed. 2001, 120, 1-6.

21. Ji, F.; Xu, J.; Liu, X.; Yin, X.; Shi, J. Natural occurrence of deoxynivalenol and zearalenone in wheat from jiangsu province, china. Food Chem. 2014, 157, 393-397.

22. Schroeder, H.; Christensen, J. Factors affecting resistance of wheat to scab caused by gibberella zeae. Phytopathology 1963, 53, 831-838.

23. Miller, J.; Young, J.; Sampson, D. Deoxynivalenol and fusarium head blight resistance in spring cereals. J. Phytopathol. 1985, 113, 359-367.

24. Cumagun, C.J.R.; Miedaner, T. Segregation for aggressiveness and deoxynivalenol production of a population of gibberella zeae causing head blight of wheat. Eur. J. Plant Pathol. 2004, 110, 789-799.

25. Snijders, C.H.A. Resistance in wheat to fusarium infection and trichothecene formation. Toxicol. Lett. 2004, 153, 37-46.

26. Homdork, S.; Fehrmann, H.; Beck, R. Effects of field application of tebuconazole on yield, yield components and the mycotoxin content of fusarium-infected wheat grain. J. Phytopathol. 2000, $148,1-6$.

27. Miedaner, T.; Schneider, B.; Geiger, H.H. Deoxynivalenol (don) content and fusarium head blight resistance in segregating populations of winter rye and winter wheat. Crop Sci. 2003, 43, 519-526.

28. Mesterhazy, A.; Logrieco, A.; Corazza, L.; Cooke, B.M. Role of deoxynivalenol in aggressiveness of Fusarium graminearum and F. Culmorum and in resistance to Fusarium head blight. Eur. J. Plant Pathol. 2002, 108, 675-684.

29. Lamper, C.; Teren, J.; Bartok, T.; Komoroczy, R.; Mesterhazy, A.; Sagi, F. Predicting don contamination in fusarium-infected wheat grains via determination of the ergosterol content. Cereal Res. Commun. 2000, 28, 337-344.

30. Chen, L.; Song, Y.; Xu, Y. Variation in the concentrations of deoxynivalenol in the spikes of winter wheat infected by fusarium graminearum schw. Acta Phytopathol. Sin. 1995, 26, 25-28.

31. Magan, N.; Hope, R.; Colleate, A.; Baxter, E.S. Relationship between growth and mycotoxin production by fusarium species, biocides and environment. Eur. J. Plant Pathol. 2002, 108, 685-690.

32. Champeil, A.; Fourbet, J.; Dore, T.; Rossignol, L. Influence of cropping system on fusarium head blight and mycotoxin levels in winter wheat. Crop Prot. 2004, 23, 531-537.

33. Birzele, B.; Meier, A.; Hindorf, H.; Krämer, J.; Dehne, H.W. Epidemiology of fusarium infection and deoxynivalenol content in winter wheat in the rhineland, germany. Eur. J. Plant Pathol. 2002, 108, 667-673.

34. Beyer, M.; Klix, M.B.; Verreet, J.-A. Estimating mycotoxin contents of fusarium-damaged winter wheat kernels. Int. J. Food Microbiol. 2007, 119, 153-158. 
35. Hope, R.; Aldred, D.; Magan, N. Comparison of environmental profies for growth and deoxynivalenol production by fusarium culmorum and f. Graminearum on wheat grain. Lett. Appl. Microbiol. 2005, 40, 295-300.

36. Snijders, C.H.A.; Krechting, C.F. Inhibition of deoxynivalenol translocation and fungal colonization in fusarium head blight resistant wheat. Can. J. Bot. 1992, 70, 1570-1576.

37. Doohan, F.M.; Weston, G.; Rezanoor, H.N.; Parry, D.W.; Nicholson, P. Development and use of a reverse transcription-pcr assay to study expression of tri5 by fusarium species in vitro and in planta. Appl. Environ. Microbiol. 1999, 65, 3850-3854.

38. Clear, R.M.; Patrick, S.K.; Vowicki, T.; Gaba, D.; Edney, M.; Babb, J.C. The effect of hull removal and pearling on fusarium species and trichothecenes in hulless barley. Can. J. Plant Sci. 1997, 77, 161-166.

39. Legzdina, L.; Buerstmayr, H. Comparison of infection with Fusarium head blight and accumulation of mycotoxins in grain of hulless and covered barley. J. Cereal Sci. 2004, 40, 61-67.

40. Wang, Y.Z.; Miller, J.D. Effects of fusarium graminearum metabolites on wheat tissue in relation to fusarium head blight resistance. J. Phytopathol. 1988, 122, 118-125.

41. Sinha, R.; Savard, M. Concentration of deoxynivalenol in single kernels and various tissues of wheat heads. Can. J. Plant Pathol. 1997, 19, 8-12.

42. Bateman, G.; Murray, G.; Gutteridge, R.; Coşlkun, H. Effects of method of straw disposal and depth of cultivation on populations of fusarium spp. In soil and on brown foot rot in continuous winter wheat. Ann. Appl. Biol. 1998, 132, 35-47.

43. Zhang, X.; Ren, L.; Tan, X.; Zang, Y.; Ma, H.; Qin, J.; Lu, W. Evaluation method of wheat Fusarium head blight resistance for genetic populations based on molecular markers. J. Nanjing Univ. (Natl. Sci.) 2005, 41, 125-132.

44. Ye, X.; Shirley, S.; Xu, H.; Du, L.; Huang, Y.; Lu, W.; Clemente, T. Transformation and identification of $B C L$ and $R l P$ genes related to cell apodosis into wheaf mediated by Agrobacterium. Acta Agron. Sin. 2005, 31, 1389-1393.

45. Shi, J.; Xu, D.; Yang, H.; Lu, Q.; Ban, T. DNA marker analysis for pyramided of fusarium head blight (fhb) resistance qtls from different germplasm. Genetica 2008, 133, 77-84.

46. Lu, Q.; Szabo-Hever, A.; Bjørnstad, A.; Lillemo, M.; Semagn, K.; Mesterhazy, A.; Ji, F.; Shi, J.; Skinnes, H. Two major resistance quantitative trait loci are required to counteract the increased susceptibility to Fusarium head blight of the dwarfing gene in wheat. Crop Sci. 2011, 51, 2430-2438.

47. Sulyok, M.; Berthiller, F.; Krska, R.; Schuhmacher, R. Development and validation of a liquid chromatography/tandem mass spectrometric method for the determination of 39 mycotoxins in wheat and maize. Rapid Commun. Mass Spectrom. 2006, 20, 2649-2659.

48. Spanjer, M.C.; Rensen, P.M.; Scholten, J.M. Lc-ms/ms multi-method for mycotoxins after single extraction, with validation data for peanut, pistachio, wheat, maize, cornflakes, raisins and figs. Food Addit. Contam. 2008, 25, 472-489.

49. Soleimany, F.; Jinap, S.; Abas, F. Determination of mycotoxins in cereals by liquid chromatography tandem mass spectrometry. Food Chem. 2012, 130, 1055-1060.

(C) 2015 by the authors; licensee MDPI, Basel, Switzerland. This article is an open access article distributed under the terms and conditions of the Creative Commons Attribution license (http://creativecommons.org/licenses/by/4.0/). 